\title{
BILATERAL RENAL ANGIOMYOLIPOMAS AND SUBEPENDYMAL GIANT CELL ASTROCYTOMA ASSOCIATED WITH TUBEROUS SCLEROSIS COMPLEX: A CASE REPORT AND REVIEW OF THE LITERATURE
}

\author{
Rambabova Bushljetik I ${ }^{1, *}$, Lazareska $\mathrm{M}^{2}$, Barbov ${ }^{3}$, Stankov $\mathrm{O}^{4}$, Filipce $\mathrm{V}^{5}$, Spasovski $\mathrm{G}^{1}$ \\ *Corresponding Author: Rambabova Bushljetik I, M.D., Ph.D., University Clinic of Nephrology, \\ Vodnjanska 17, 1000 Skopje, Republic of North Macedonia. Tel.: +389-214-7191. Mobile: +389-72- \\ 216-581. Fax: +389-231-1188. E-mail: irambabova@yahoo.com
}

\begin{abstract}
Tuberous sclerosis complex (TSC) is an autosomaldominant multi system disorder. The genetic basis of the disorder is mutations in the TSC1 or TSC2 gene, which leads to over activation of the mammalian target of rapamycin (mTOR) protein complex and results in development of benign tumors in different body systems such as brain, skin, lungs and kidney. The mTOR inhibitors are presently the main treatment option for patients with TSC. We here report a 21-year female patient with large bilateral angiomyolipoma (AML) in both kidneys with longest diameter more than $12.3 \mathrm{~cm}$ and subependymal giant cell astrocytoma (SEGA). Treatment with everolimus (EVE) was initiated at a dose of $10.0 \mathrm{mg} /$ day and continued during the following 3 years. Magnetic resonance imaging (MRI) was performed before treatment with everolimus was initiated, and consequently at 12 and 36 months for follow-up of the efficacy of the treatment. After 3 years, the total size of largest AML decreased by $\sim 24.0 \%$ in the longest diameter. A reduction of the total size of SEGA was also observed. The most common adverse effect of treatment was stomatitis grades 3 to 4 and one febrile episode associated with skin rash that required a reduced dose of EVE. In conclusion, the everolimus treatment improved even such a large renal AML and the effect persisted during the long-term administration with a small number of

\footnotetext{
${ }^{1}$ University Clinic of Nephrology, Skopje, Republic of North Macedonia

${ }^{2}$ Institute of Radiology, Skopje, Republic of North Mace-donia

${ }^{3}$ University Clinic of Neurology, Skopje, Republic of North Macedonia

${ }^{4}$ University Clinic of Urology, Skopje, Republic of North Macedonia

${ }^{5}$ University Clinic of Neurosurgery, Skopje, Republic of North Macedonia
}

adverse effects. A positive effect was observed on the brain tumor as well.

Keywords: Tuberous sclerosis complex (TSC); Angiomyolipoma (AML); Subependymal giant cell astrocytoma (SEGA); Everolimus (EVE).

\section{INTRODUCTION}

Tuberous sclerosis complex (TSC) is a rare disease, with a birth rate of 1 in 6,000 to 1 in 10,000 newborns [1]. It is a multisystemic, autosomal dominant condition that can result in formation of hamartomas in multiple organs, mainly in brain, kidney, skin and lung. The two thirds of affected patients have sporadic mutations [2].

The British dermatologist John James Pringle first observed papular facial rash in a female patient with intellectual impairment, describing it as "adenoma sebaceum" [3]. The French neurologist Désiré-Magloire Bourneville described potato-like tumors in the brain and associated them with the cutaneous manifestations and other clinical symptoms [4]. Hence, a historical text appeared as the "Bourneville-Pringle disease" [5,6].

At a molecular basis, TSC results from a mutation in one of two TSC1 and TSC2 genes (located in chromosomes 9 and 16, respectively). These two genes encode two proteins (hamartin and tuberin), form intracellular complexes and physiologically inhibit a serine-threoninekinase, known as mTOR (mammalian target of rapamycin). Their complete loss allows unregulated stimulation of cell growth and proliferation [7].

The first TSC Consensus Conference was held in 1998 and the recommendations for diagnosis and clinical management of patients with TSC were developed [8]. At the second International TSC Consensus Conference 
(2012), these criteria were reviewed and updated and recommendations for diagnosis, surveillance and management of TSC patients were issued [9].

The mTOR inhibitor rapamycin, and later the rapamycin derivate, everolimus, played a significant role in solid organ transplant protocols to prevent rejection, in oncology as an anticancer target therapy and for elution of vascular stents in interventional cardiology [10]. In 2010, everolimus became the first approved therapy by the US Food and Drug Administration (FDA) for treatment of TSC-associated subependymal giant cell astrocytoma (SEGA). Later, in 2012, everolimus was also approved by the FDA to treat renal angiomyolipomas (AMLs), in TSC patients [11].

Diagnosis of TSC can be confirmed with clinical diagnostic criteria and gene testing, but in $10.0-25.0 \%$ of patients there is no gene mutation confirmed. Clinical diagnostic criteria consist of 11 major and six minor features. Definitive diagnosis can be confirmed with presence of two major or one major and two minor futures [9].

About $85.0 \%$ of patients with TSC during childhood and adolescence manifest seizures, cognitive and/or behavioral problems (autism and autism spectrum disease). A subset of adult patients have normal mental status. The main brain lesions include cortical tubers, subependymal nodules and SEGA present in only $5.0-15.0 \%$ of TSC patients. Subependymal giant cell astrocytoma can lead to ventricular enlargement and hydrocephalus increasing the rate of morbidity and mortality among this group of patients [12].

Angiomyolipomas are the most common renal lesions ( $\sim 80.0 \%$ of cases) in TSC patients. They are typically multiple and bilateral, composed of abnormal blood vessels, immature smooth muscle and fat cells, and progressively enlarge from the first years of life and adolescence. Spontaneous bleeding may occur due to abnormal vasculature and aneurysm development. The size of tumors (AMLs) $>4$ $\mathrm{cm}$ is risk factors for bleeding. Except AMLs, TSC patients have been diagnosed also with multiple renal cysts [13].

Lung involvement, called lymphangioleiomyomatosis (LAM), is characterized by replacement of alveolar tissue by cystic changes and proliferation of the smooth muscle cells in pulmonary parenchyma. This condition is the third most common cause of TSC morbidity, affecting almost exclusively reproductive age females with TSC [14].

Cutaneous manifestations are observed in $90.0 \%$ of patients and present the most visible features of TSC. The most common are hypopigmented macules as pathognomonic sign for early diagnosis. Facial angiofibromas are observed in $85.0-90.0 \%$ of cases [15].

\section{CASE REPORT}

A 21-year-old female patient was diagnosed with sporadic TSC at the age of 12. She was the first child in the family, born at term with placenta previa. Because of presence of multiple hypopigmented macules on the skin at the time of birth, she was transferred to the Neonatology Department at the University Pediatric Clinic, Skopje, Republic of North Macedonia. However, the exact diagnosis was not established. At 1 year of age, the first convulsion was reported and treatment with phenobarbitol was initiated. At the age of 5, multiple facial angiofibromas were noted in the medical records. Furthermore, some cosmetic procedures were performed. In 2010, at the age of 12, a new episode of convulsions appeared, and she was hospitalized. A complete check-up was performed and genetic analysis confirmed a deletion of exon 1 of the TSC2 gene and the upstream region of the TSC2 gene by multiplex ligation probe amplification (MLPA) method (MRC-Holland, Amsterdam, The Netherlands). No presence of mutation in the genetic analysis of the parents was confirmed, and it was described as a de novo mutation. Multiple major and minor features were described in the medical reports (Table 1).

Table 1. The proband's clinical diagnostic criteria.

\begin{tabular}{|l|l|}
\hline Major Features & Minor Features \\
\hline Angiomyolipomas & Multiple renal cysts \\
\hline Cortical tubers & Gingival fibromas \\
\hline SEGA & \\
\hline Hypopigmented macules & \\
\hline Fagial angiofibromas & \\
\hline Cardiac rhabdomyoma & \\
\hline
\end{tabular}

SEGA: subependymal giant cell astrocytoma.

Treatment with mTOR inhibitor was suggested, but not initiated. In 2014, she was regularly transferred to the University Clinic of Nephrology, Skopje, Republic of North Macedonia, as an adult patient. Another investigation and laboratory tests were performed there. The patient was asymptomatic, without the presence of new episodes of epilepsy, flank pain and abnormal urinary sediment.

Ultrasonography of the urinary tract revealed multiple heterogenous lipid-rich lesions present in both kidneys. The largest formation in the upper pole of the right kidney had the longest diameter of $\sim 11 \mathrm{~cm}$. She was referred to the urologist, but surgical treatment or an embolization procedure was not suggested. In 2015, according to the guidelines for treatment of TSC patients, systematic therapy with everolimus was initiated. 
Magnetic resonance imaging of the urinary tract and brain were performed before initiation of everolimus treatment (Figures 1 and 2). After 12 months of treatment,

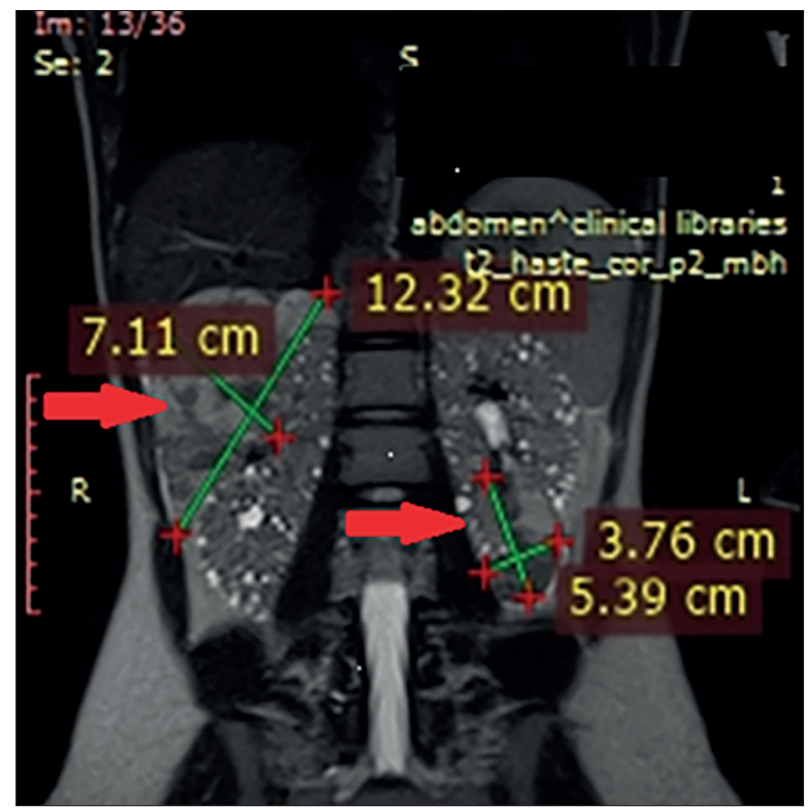

Figure 1. At the upper pole of the right kidney a large AML, longest diameter of $12.3 \times 7.1 \mathrm{~cm}$ (arrow left) with heterogenous density, presence of microaneurisms at the posterior and lateral segments, with a dominant lipid component revealed on the urinary tract MRI (red arrow). At the lower pole of the left kidney, an AML with the dimension of $5.3 \times 3.7 \mathrm{~cm}$ (arrow right) and other multiple AMLs with dimensions of 5-10 $\mathrm{mm}$ were found, as well as multiple cysts.

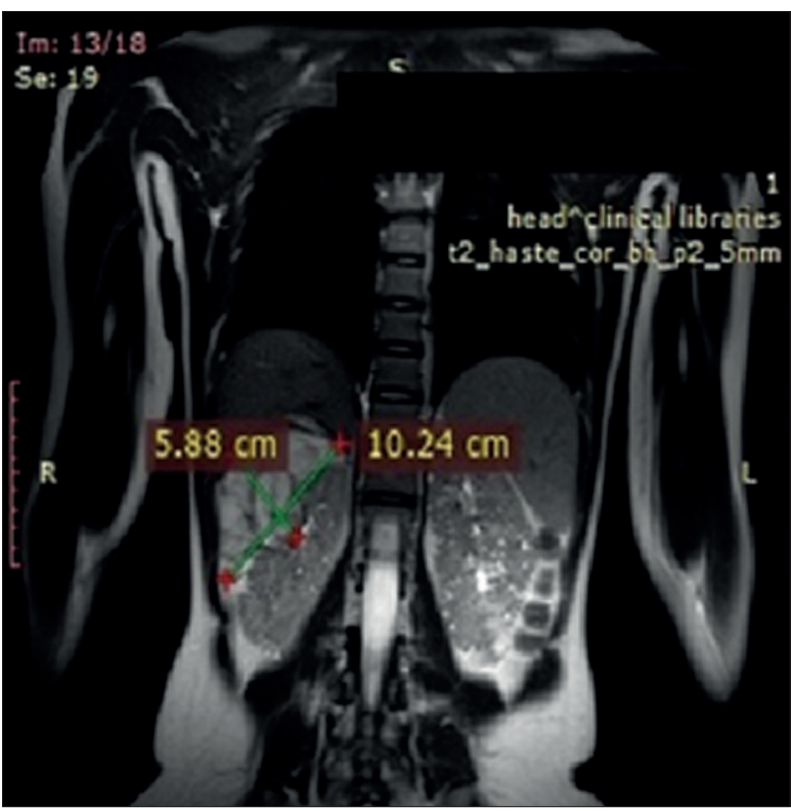

Figure 3. Magnetic resonance imaging of the urinary tract at 12 months after everolimus initiation. reduction of the renal tumors and SEGA were registered (Figures 3 and 4). At 36 months, $24.0 \%$ reduction in the longest diameter of the largest AML in right kidney was

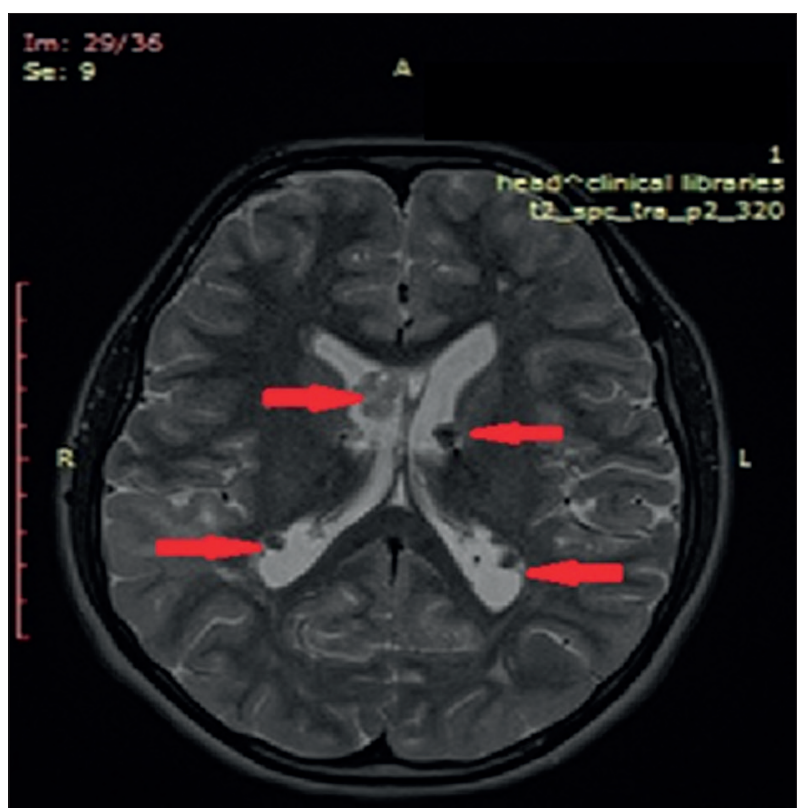

Figure 2. On the brain MRI, multiple lesions as subependimal nodules, subcortical tubers and largest tumor mass presented in foramen Monro as SEGA (diameter $3.0 \times 1.5 \mathrm{~cm}$ ) were described.

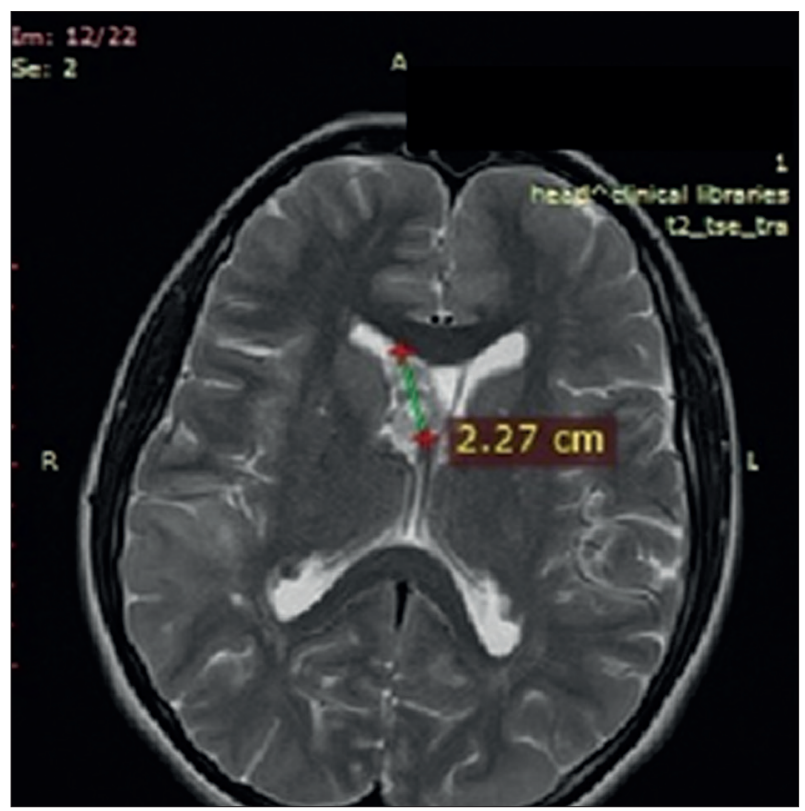

Figure 4. Magnetic resonance imaging of the brain at 12 months after everolimus initiation. 
achieved. Reduction of SEGA was also observed (Figures 5 and 6 ). All biochemical parameters remained stable during the follow-up period. Normal renal function without a new onset of proteinuria was observed (Table 2).

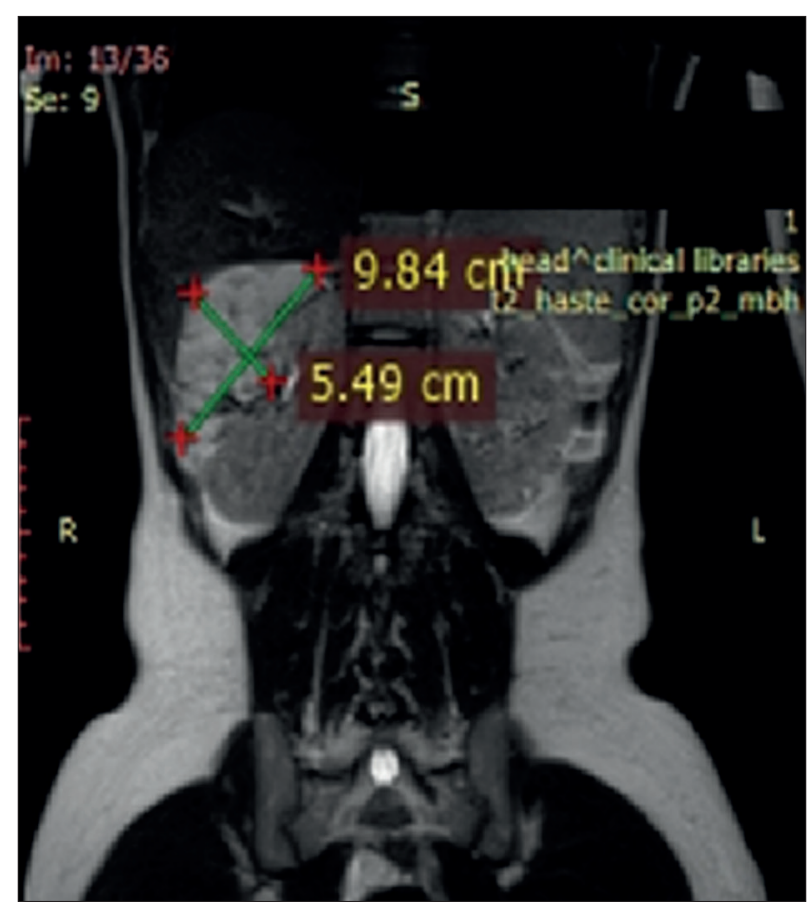

Figure 5. Magnetic resonance imaging of the urinary tract at 36 months after everolimus treatment initiation.

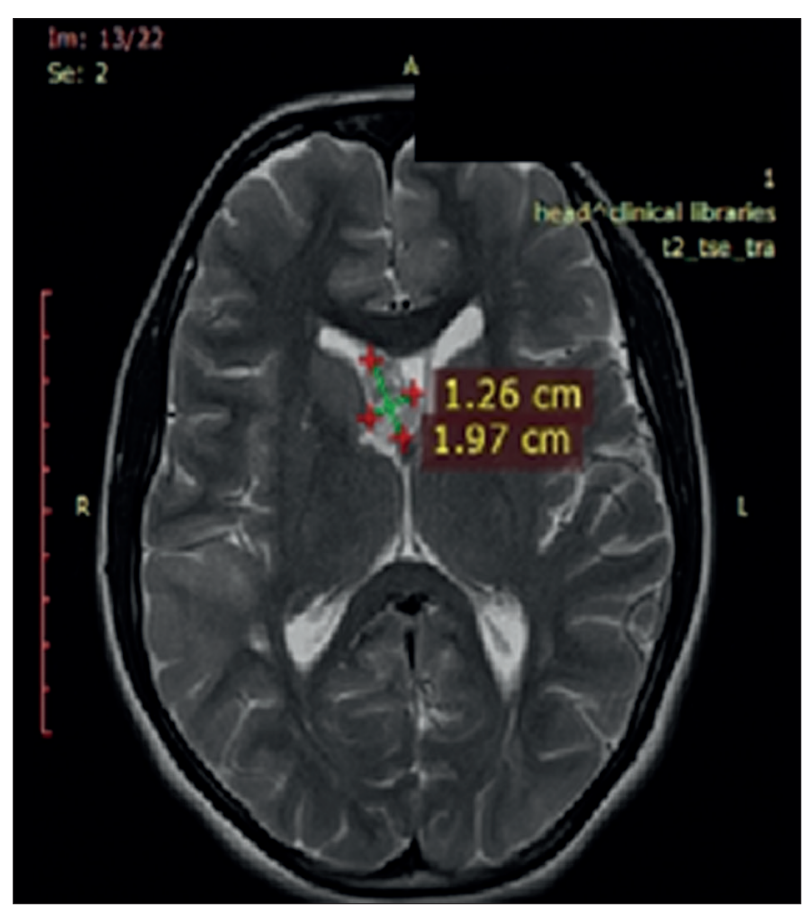

Figure 6. Magnetic resonance imaging of the brain at 36 months after everolimus treatment initiation.
Table 2. Biochemical laboratory findings in the follow-up period.

\begin{tabular}{|l|c|c|c|}
\hline Parameters & First Year & Second Year & Third Year \\
\hline $\mathrm{Hb}(\mathrm{g} / \mathrm{dL})$ & 12.1 & 12.4 & 12.6 \\
\hline $\mathrm{RBC}\left(10^{12} / \mathrm{L}\right)$ & 3.9 & 4.1 & 4.0 \\
\hline Platelets $\left(10^{9} / \mathrm{L}\right)$ & 245.0 & 254.0 & 256.0 \\
\hline Protein/albumin $(\mathrm{g} / \mathrm{dL})$ & $79.0 / 41.0$ & $82.0 / 42.0$ & $81.0 / 42.0$ \\
\hline SCR $(\mu \mathrm{mol} / \mathrm{L})$ & 62.0 & 61.0 & 63.0 \\
\hline BUN $(\mathrm{mmol} / \mathrm{L})$ & 3.8 & 2.9 & 3.5 \\
\hline Cholesterol $(\mathrm{mmol} / \mathrm{L})$ & 4.0 & 4.1 & 4.0 \\
\hline HDL $(\mathrm{mmol} / \mathrm{L})$ & 1.2 & 1.3 & 1.2 \\
\hline LDL $(\mathrm{mmol} / \mathrm{L})$ & 2.3 & 2.2 & 2.1 \\
\hline Triglycerides $(\mathrm{mmol} / \mathrm{L})$ & 0.96 & 1.10 & 1.10 \\
\hline CRP $(\mathrm{mg} / \mathrm{L})$ & 1.9 & 1.2 & 1.6 \\
\hline Proteinuria $(\mathrm{g} / 24$ hours $)$ & 0.13 & 0.11 & 0.17 \\
\hline
\end{tabular}

Hb: hemoglobin; RBC: red blood cell count; SCR: serum creatinine; BUN: blood urea nitrogen; HDL: high-density lipoproteins; LDL: low-density lipoproteins; CRP: c-reactive protein test.

\section{DISCUSSION}

According to the established diagnostic criteria, our case displayed many major and two minor features for "definitive diagnosis," also confirmed by genetic testing. The different disease presentation required a multi disciplinary approach for the patient to manage the epilepsy and renal involvement.

Our patient started with everolimus treatment in the late phase of the disease presentation, with large AMLs in both kidneys $(>12 \mathrm{~cm})$. Everolimus tablets, $10 \mathrm{mg} /$ day. were administered, with blood trough levels in the range of 5.0$15.0 \mathrm{ng} / \mathrm{mL}$ in accordance with the guidelines. Renal AMLs are the most frequent features of TSC as benign tumors. In the general population the prevalence of AML is rare $(0.02-$ $0.29 \%$ ) of both males and females. Treatment of renal AML depends on its presentation [16]. According the guidelines for asymptomatic AMLs of $>3 \mathrm{~cm}$, they should be treated with mTOR inhibitors. In our case, the reduction of AML in the follow-up period was lower than presented literature results, as well as the reduction of the SEGA volume was not similar to the published studies, but still acceptable.

Phase III EXIST-1 study (NCT00789828) included 117 patients at the age of 0.8-26.6 years with TSC-associated growing SEGA. Patients were randomly included in a 2:1 ratio to receive everolimus $(n=78)$ and placebo $(n=39)$. The median follow-up period was 9.7 months when $35.0 \%$ of the patients in the everolimus treatment group achieved $>50.0 \%$ reduction in size of SEGA $v s .0 .0 \%$ of the patients in the placebo group. The exploratory end points, AML re- 
sponse rate ( $>1 \mathrm{AML}>1 \mathrm{~cm}$ in the longest diameter) $53.0 \%$ achieved response rate $v s .0 .0 \%$ in the placebo group [17].

The everolimus for AML associated with TSC or sporadic lymphangiomyomatosis (EXIST-2) trial has confirmed the previous reports. It was a multi center, randomized, double blind, placebo-controlled, phase III trial of 118 patients with a definite TSC diagnosis and at least one AML $>3 \mathrm{~cm}$ that showed $42.0 \%$ reduction of AML volume in everolimus compared to $0.0 \%$ in the placebo group [18].

After 3 years of treatment, our patient reached approximately $24.0 \%$ reduction in the longest diameter of AML. No evidence of new AMLs or episodes of bleeding were observed.

An extension phase of the EXIST study included 112 patients who received $>1$ dose of everolimus, and $58.0 \%$ achieved AML response rate. Almost all patients (97.0\%) achieved reduction in renal lesion volumes during the study period. Median duration of everolimus exposure was 46.9 months. Approximately $14.3 \%$ of patients experienced progression in AML size [19]. While previous reports have largely assessed the effect of everolimus for AMLs with longest diameter $<10 \mathrm{~cm}$, another case report included three patients suggesting this drug might also be effective for huge lesions of $>20 \mathrm{~cm}$ in diameter [20].

Of note, in our case during the period of treatment, some adverse events were registered. A few episodes of aphthous stomatitis requiring reduction of the dose of everolimus were observed. One febrile episode with zosterlike cutaneous rash on the lower extremity was treated at University Clinic of Dermatovenerology, Skopje, Republic of North Macedonia, with temporary everolimus treatment interruption.

Facial angiofibromas were features of the disease with the highest response rate to treatment with good psychological effect on the patient. In the reported studies, proteinuria was one of the adverse events, but in our case the patient did not experience proteinuria, and had normal renal function for the whole period of treatment [18,19].

Due to the presence of a large brain structural manifestation, continuous follow-up by a neurologist and a neurosurgeon was performed. The majority of TSC patients have neurological symptoms, $\sim 90.0 \%$ of affected individuals experience seizures and almost half also experience cognitive impairments, autism, or other behavioral disorders. Epilepsy is seen in $70.0-90.0 \%$ of patients, most commonly presenting in the first year of life [12]. Our patient had normal mental status without autism and/or behavioral difficulties. However, seizures were present from the first year of life, with prescribed therapy till 5 years. At the age of 12 years, when the new onset of seizures was registered, an anticonvulsive treatment was reinitiated. After many years free of seizures, the anticonvulsive therapy was again ceased. Thus, after 3 years undergoing everolimus therapy, a new episode of seizure was reported and anticonvulsive therapy was administered. The patient was placed on lamotrigin. The MRI findings excluded hydrocephalus without necessity of surgical treatment. Based on the literature, surgical intervention of SEGA $>3$ $\mathrm{cm}$ has $67.0 \%$ risk of surgery-related complications and surgery on tumors $>4 \mathrm{~cm}$ was associated with $73.0 \%$ risk of complications [21,22].

It is recommended that SEGAs are MRI-monitored every 1-3 years in patients younger than 25 , as these tumors usually grow in children and young adolescents, but do not have a tendency to grow in adulthood [21,22]. Similar case reports are found in the literature with similar disease presentation and medical treatment [23].

Conclusions. Tuberous sclerosis complex is a multi systemic disorder with different symptom presentations and the highest rate of morbidity and mortality associated with renal and brain manifestations. Treatment with everolimus is beneficial for even such large AMLs, and the positive impact persisted during a long-term administration with a low rate of adverse effects. A positive impact of everolimus treatment was also observed on the brain tumors, especially SEGA.

Declaration of Interest. The authors report no conflicts of interest. The authors alone are responsible for the content and writing of this article.

\section{REFERENCES}

1. O'Callaghan FJ, Shiell AW, Osborne JP, Martyn CN. Prevalence of tuberous sclerosis estimated by capturerecapture analysis. Lancet. 1998; 351(9114): 1490.

2. Crino PB, Nathanson KL, Henske EP. The tuberous sclerosis complex. N Engl J Med. 2006; 355(13): 1345-1356.

3. Jansen FE, van Nieuwenhuizen O, van Huffelen AC. Tuberous sclerosis complex and its founders. J Neurol Neurosurg Psychiatry. 2004; 75(5): 770.

4. Brigo F, Lattanzi S, Trinka E, Nardone R, Bragazzi NL, Ruggieri M, et al. First descriptions of tuberous sclerosis by Désiré-Magloire Bourneville (18401909. Neuro-pathology. 2018; 38(6):577-582.

5. Rodrigues DA, Gomes CM, Costa IM. Tuberous sclerosis complex. Ann Bras Dermatol. 2012; 87(2): 184-196.

6. Portocarrero LKL, Quental KN, Samorano LP, de Oliveira ZNP, Rivitti-Machado MCDM. Tuberous sclerosis complex: review based on new diagnostic criteria. Ann Bras Dermatol. 2018; 93(3): 323-331. 
7. Pirson Y. Tuberous sclerosis complex-associated kidney angiomyolipoma: From contemplation to action. Nephrol Dial Transplant. 2013; 28(7): 1680-1685.

8. Roach ES, Gomez MR, Northrup H. Tuberous sclerosis complex consensus conference: Revised clinical diagnostic criteria. J Child Neurol. 1998; 13(12): 624-628.

9. Northrup H, Krueger DA; International Tuberous Sclerosis Complex Consensus Group. Tuberous sclerosis complex diagnostic criteria update: Recommendations of the 2012 International Tuberous Sclerosis Complex Consensus Conference. Pediatr Neurol. 2013; 49(4): 243-254.

10. Gabardi S, Baroletti SA. Everolimus: A proliferation signal inhibitor with clinical applications in organ transplantation, oncology, and cardiology. Pharmacotherapy. 2010; 30(10): 1044-1056.

11. Capal JK, Franz DN. Profile of everolimus in the treatment of tuberous sclerosis complex: An evidencebased review of its place in therapy. Neuropsychiatr Dis Treat. 2016; 12: 2165-2172.

12. Curatolo P, Moavero R, de Vries PJ. Neurological and neuropsychiatric aspects of tuberous sclerosis complex. Lancet Neurol. 2015; 14(7): 733-745.

13. Budde K, Gaedeke J. Tuberous sclerosis complexassociated angiomyolipomas: Focus on mTOR inhibition. Am J Kidney Dis. 2012; 59(2): 276-283.

14. McCormack FX, Inoue Y, Moss J, Singer LG, Strange C, Nakata K, et al. Efficacy and safety of sirolimus in lymphangioleiomyomatosis. N Engl J Med. 2011; 364(17): 1595-1606.

15. Jacks SK, Witman PM. Tuberous sclerosis complex: An update for dermatologists. Pediatr Dermatol. 2015; 32(5): 563-570.

16. Murray TE, Doyle F, Lee M. Transarterial embolization of angiomyolipoma: A systematic review. J Urol. 2015; 194(3): 635-639.
17. Franz DN, Belousova E, Sparagana S, Bebin EM, Frost M, Kuperman R, et al. Efficacy and safety of everolimus for subependymal giant cell astrocytomas associated with tuberous sclerosis complex (EXIST-1): A multicentre, randomised, placebo-controlled phase 3 trial. Lancet. 2013; 381(9861): 125-132.

18. Bissler JJ, Kingswood JC, Radzikowska E, Zonnenberg BA, Frost M, Belousova E, et al. Everolimus for angiomyolipoma associated with tuberous sclerosis complex or sporadic lymphangioleiomyomatosis (EXIST-2): A multicentre, randomised, double-blind, placebocontrolled trial. Lancet. 2013; 381(9869): 817-824.

19. Bissler JJ, Kingswood JC, Radzikowska E, Zonnenberg BA, Belousova E, Frost MD, et al. Everolimus long-term use in patients with tuberous sclerosis complex: Four-year update of the EXIST-2 study. PLoS One. 2017; 12(8): e0180939.

20. Toriu N, Mizuno H, Sawa N, Sumida K, Suwabe $\mathrm{T}$, Hayami N, et al. Everolimus reduces the size of tuberous sclerosis complex-related huge renal angiomyolipomas exceeding $20 \mathrm{~cm}$ in the longest diameter. Case Rep Oncol. 2018; 11(2): 258-267.

21. Kotulska K, Borkowska J, Roszkowski M, Mandera M, Daszkiewicz P, Drabik K, et al., Surgical treatment of subependymal giant cell astrocytoma in tuberous sclerosis complex patients. Pediatr Neurol. 2014; 50(4): 307-312.

22. Roth J, Roach ES, Bartels U, Jóźwiak S, Koenig MK, Weiner HL, et al.. Subependymal giant cell astrocytoma: Diagnosis, screening, and treatment. Recommendations from the International Tuberous sclerosis Complex Consensus Conference 2012. Pediatr Neurol. 2013; 49(6): 439-444.

21. Stein JR, Reidman DA. Imaging manifestations of a subependymal giant cell astrocytoma in tuberous sclerosis. Case Rep Radiol. 2016; 2016: 3750450. 